\title{
A Clinico-Epidemiological Study of Pediatric Hair and Scalp Disorders
}

\author{
Mohammed M.S. Younis*1, Waleed Ahmed Mahmoud ${ }^{2}$ \\ Departments of ${ }^{1}$ Pediatrics and ${ }^{2}$ Dermatology and Andrology, Al-Azhar University (Assiut), Assiut, Egypt \\ *Corresponding author: Mohammed M.S. Younis, Mobile: (+20)01117259456, \\ E-Mail: mmsyonis@yahoo.com
}

\begin{abstract}
Background: Hair and scalp disorders are a common complaint in dermatology clinics and can be caused by several conditions, reflected in a specific diagnosis. Also, this problem is of prime concern in the pediatric population as it is associated with more significant psychological consequences in this growing age group.

Objective: To evaluate the clinical and epidemiological profile of hair and scalp disorders in children attending to the Pediatrics and Dermatology Outpatient Clinics.

Patients and methods: The current study included 1000 children attending the outpatient pediatric and Dermatology clinics in Alazher University Assiut within the period from June 2019 to April 2020, from them 200 children were diagnosed with hair disorder. All children were subjected to; thorough history taking, general and local examination, and dermoscopic examination.

Results: In the present study we noticed that; male to female ratio was $0.8: 1$. The age groups with the largest and smallest numbers of children were those of children aged 10-12 and 1-3 years, respectively. Alopecia areata represented $15 \%$ of the studied patients. $10 \%$ of the included patients had seborrheic dermatitis. Pediculosis capitis was evident in $14 \%$ of the studied population. Tinea capitis was evident in $15 \%$ of the study population. Infectious causes were the most common causes of hair disorders in our study. Alopecia areata represented $15 \%$ of the studied patients.there is a significant difference value in tinea capitis and pediculosis capitis in urban than rural areas and there is a significant difference value in seborrheic dermatitis and alopecia areata in rural than urban areas. In the current study, malnutrition was evident in $30 \%$ of children with scalp diseases.

Conclusion: Hair and scalp disorder in children is a common complaint in pediatrics clinics, and it is considered a challenge for pediatricians for reaching a proper diagnosis and therapy. Early management is needed, as it affects the normal physical and mental growth of children.
\end{abstract}

Keywords: Clinical and epidemiological profile of hair, Scalp disorders, Children.

\section{INTRODUCTION}

Hair and scalp disorders in infants and children are a common occurrence and may constitute a complex clinical problem, and they are also a source of anxiety and concern for patients and families ${ }^{(\mathbf{1})}$.

Hair disorders in children can be congenital or acquired and may be associated or not with defects in hair structure. In some cases, they may be a part of serious hereditary syndromes ${ }^{(2)}$.

Common causes of hair disorders in children include folliculitis and furunculosis, pediculosis, alopecia areata, and tinea capitis (TC). In addition to the above-mentioned causes, other less common causes include pityriasis capitis, telogen effluvium, folliculitis decalvans, premature graying of hair, piebaldism, trichotillomania, and congenital atrichia (3). No extensive report exists regarding the epidemiology of these disorders in children ${ }^{(4)}$.

Hair loss is not an uncommon problem in the pediatric group but has patterns that are different from those seen in adults. In addition, this problem is of particular concern in the pediatric group, as it is associated with more significant psychological consequences in this growing age group ${ }^{(5)}$.

Common causes of hair loss in children include telogen effluvium, tinea capitis, bacterial infections, traction alopecia, trichotillomania, alopecia areata. In addition to the previous, other less common causes of hair loss can be seen including thyroid disorders, illnesses, such as systemic lupus erythematosus, diabetes mellitus, or iron deficiency anemia, malnutrition, structural abnormalities of the hair shaft that usually results in easy breakage and dry brittle hair, scalp infection by various etiological agents staphylococcus aureus and streptococcus pyogens are the most common ${ }^{(6)}$.

This study was aiming to evaluate the clinical and epidemiological profile of hair and scalp disorders in children attending the pediatric outpatient clinic.

\section{PATIENTS AND METHODS}

This study was carried out as a cross-sectional study which included 1000 children attending the outpatient in pediatric and Dermatology clinics in Alazher University Assiut within the period from June 2019 to April 2020, from emth 200 children were diagnosed as hair and scalp disorder.

\section{All children's were subjected to:}

(A) Thorough history taking:

1- The data collected: age, sex, and clinical presentations (patchy or diffuse hair loss, presence of itching or scales, affected site, and 
the progression of the problem, and hair loss in the body other than the scalp).

2- Dietary habits: number of meals per day, eating breakfast, eating regular meals, eating fruits and vegetables, eating snacks between meals, eating fast food, and drinking soft drinks.

3- Nutritional pattern and Lifestyle assessment.

4- Developmental history.

5- Perinatal history.

6- Past history and family history.

7- Social history: residence, maternal and paternal education, and maternal and paternal occupation.

(B) Examination:

1- Vital signs: BP, temperature, respiratory rate, heart rate

2-Anthropometric measures: Length/height for age, weight for age, weight for length, weight for height, and body mass index for age.

Each subject following parameters was measured like height and weight. Anthropometric measurements were taken by using standard protocols given by Weiner and Lourie. Stature was taken with the help of anthropometry in the standard arm hanging position body weight was measured by using spring balance with minimum clothing.

- Weight measurement in kilograms by calibrated scale without shoes and the child wearing light clothes. Children 2 to 19 years of age are weighed standing on a beam balance or electronic child and adolescent scale, provided they can stand on their own. A child 2 to 19 years of age should be weighed wearing lightweight outer clothing. Shoes, hats or bulky items such as coats/jackets and sweaters should be removed ${ }^{(7)}$.

- Height measurement is the measurement from the crown of the head (the superior point) to the bottom of the feet. Height is always measured standing. Remove shoes, hat, and bulky clothing such as coats/jackets and sweaters, remove or undo hairstyles and hair accessories that interfere with taking a measurement. Ask the child to stand against the stadiometer, with heels together, legs straight, arms at sides, and shoulders relaxed, the child is measured standing with heels, buttocks, shoulders, and head touching a flat upright surface, the child should be looking straight ahead in the Frankfort Horizontal Plane, bring the perpendicular headpiece down to touch the crown of the head with enough pressure to compress the hair, measurer's eyes should be parallel with the headpiece to read the measurement. Immediately record the height to the nearest $0.1 \mathrm{~cm}^{(7)}$.

- BMI was calculated as weight in kilograms divided by the square of the height in meters [weight in $\mathrm{kg} /($ height in $\mathrm{m}) 2]^{(\mathbf{8})}$.

Height, weight, and body mass index were plotted on the Egyptian growth charts ${ }^{(\mathbf{9})}$.
3- Assessment of Malnutrition: Nutritional status of the children was assessed by anthropometric measurements. The anthropometric classification was used for the assessment of malnutrition. Based on the age, body weight, and height, several indices such as weight - for - age, height - for - age and BMI - for - age have been suggested. Undernutrition that is Wasting and stunting were defined according to Water low's classification.

\section{Category of malnutrition according to BMI value} as per who cut-offs:

- < 16.0:Severe malnutrition.

- $\geq 16.0$ to $<17.0$ : Moderate malnutrition.

- $\geq 17.0$ to $<18.5$ : Mild malnutrition.

- $\geq 18.5$ to $<25.0$ : Normal nutritional status (10).

4- Examination for the presence of dysmorphic features: Including a depressed nasal bridge, lid fissures that slant downward, and eyes appearing to be abnormally far apart. Sparse hair is notable

5- Routine general clinical examination: Cardiac examination, abdominal examination, neurological examination, chest examination.

6- Local examination: Scalp examination included the skin of the scalp (presence of erythema, scales, and follicular plugging). The hair examination included the recording of hair color, texture, fragility, and examination of the hair root. Also, Wood's light examination, skin and scalp scrapings for $\mathrm{KOH}$ (potassium hydroxide) smear and mycologic studies, and bacteriology were done for specific diagnostic cases. Microscopy for the shed hair and dermoscopy was done in some cases. In addition to the scalp, other hairy sites were examined for hair loss (including eyebrows, eyelashes). Nail and teeth were examined for any abnormalities.

7- Dermoscopic examination: Patients were subjected to dermoscopic examination using micro viewer dermoscopy VER2.2a STR and science company-USA as the patients lie in sitting position and dermoscopy was applied to a fixed area of the front of the scalp by using a lens of a 70-fold magnification then photos were taken.

Ethical approval and written informed consent: Approval of the study was obtained from $\mathrm{Al}$ Azhar University's academic and ethical committee. Every patient or parent signed informed written consent for participation in the study.

\section{Statistical methods}

Data were analyzed with SPSS (statistical package for the Social Science, Chicago, IL). Data were expressed using descriptive statistics (mean and standard deviation). 
RESULTS

Table (1): Age and Sex of the included patients

\begin{tabular}{|c|c|c|c|c|}
\hline \multirow[t]{2}{*}{$\begin{array}{c}\text { Age } \begin{array}{c}\text { (mean } \pm \text { SD }) \\
(\text { years })\end{array} \\
\end{array}$} & \multicolumn{4}{|c|}{$5.5 \pm 3.1$} \\
\hline & No & $\%$ & $\chi^{2}$ & P-value \\
\hline$<5$ years & 90 & 45 & \multirow{4}{*}{$\begin{array}{c}x \\
70.3\end{array}$} & \multirow{3}{*}{0.000} \\
\hline 5-10 years & 97 & 48.5 & & \\
\hline$>10$ years & 13 & 6.5 & & \\
\hline \multicolumn{4}{|l|}{ Sex: } & \\
\hline Male & 90 & 45 & \multirow[t]{2}{*}{2} & \multirow[t]{2}{*}{0.157} \\
\hline Female & 110 & 55 & & \\
\hline
\end{tabular}

This table showed the male to female ratio was $0.8: 1$. The age groups with the largest and smallest numbers of children were those of children aged 10-12 and 0-3 years, respectively.

Table (2): Nutritional status of the included patients

\begin{tabular}{|c|c|c|c|c|c|}
\hline \multicolumn{2}{|c|}{ BMI $\left(\mathrm{Kg} / \mathrm{m}^{2}\right)$} & \multicolumn{4}{|c|}{$16.8 \pm 3.2$} \\
\hline \multirow{5}{*}{ Nutritional status } & & No & $\%$ & $\chi^{2}$ & P-value \\
\hline & Normal nutrition & 84 & 42 & \multirow{3}{*}{110} & \multirow{4}{*}{0.000} \\
\hline & Mild malnutrition & 89 & 44.5 & & \\
\hline & Moderate malnutrition & 22 & 11 & & \\
\hline & Severe malnutrition & 5 & 2.5 & & \\
\hline
\end{tabular}

This table showed malnutrition was evident in $58 \%$ of children with scalp diseases.

Table (3): Distribution of the included patients regarding hair and scalp diseases

\begin{tabular}{|c|c|c|c|c|}
\hline Hair and scalp disease & No & $\%$ & $\chi^{2}$ & P-value \\
\hline Hair shaft disease & 3 & 1.5 & \multirow{14}{*}{163} & \multirow{14}{*}{0.000} \\
\hline Telogen effluvium & 16 & 8 & & \\
\hline Tractional alopecia & 16 & 8 & & \\
\hline Tinea capitis & 35 & 17.5 & & \\
\hline Seborrheic dermatitis & 38 & 19 & & \\
\hline Multiple boils in the scalp & 15 & 7.5 & & \\
\hline Pediculosis capitis & 28 & 14 & & \\
\hline Alopecia areata & 30 & 15 & & \\
\hline Vitilligo in scalp & 1 & 0.5 & & \\
\hline Impetigo in scalp & 4 & 2 & & \\
\hline Cicatritial alopecia & 7 & 3.5 & & \\
\hline Toxic alopecia & 2 & 1 & & \\
\hline Post traumatic alopecia & 3 & 1.5 & & \\
\hline Sebaceous cyst & 2 & 1 & & \\
\hline
\end{tabular}


Table (4): Comparison between different lesions regarding age group

\begin{tabular}{|c|c|c|c|c|c|}
\hline Hair and scalp disease & $\begin{array}{c}<5 \text { years } \\
(\mathrm{N}=90)\end{array}$ & $\begin{array}{c}5-10 \text { years } \\
(\mathrm{N}=98)\end{array}$ & $\begin{array}{c}>10 \text { years } \\
(\mathrm{N}=12)\end{array}$ & $\chi^{2}$ & P-value \\
\hline Hair shaft disease & $2(2.2 \%)$ & $1(1 \%)$ & $0(0 \%)$ & \multirow{14}{*}{45} & \multirow{14}{*}{0.000} \\
\hline Telogen effluvium & $10(11.1 \%)$ & $1(1 \%)$ & $5(41.7 \%)$ & & \\
\hline Tractional alopecia & $2(2.2 \%)$ & $14(14.3 \%)$ & $0(0 \%)$ & & \\
\hline Tinea capitis & $13(14.4 \%)$ & $20(20.4 \%)$ & $2(16.7 \%)$ & & \\
\hline Seborrhic dermatitis & $26(28.9 \%)$ & $9(9.1 \%)$ & $3(24 \%)$ & & \\
\hline Multiple boils in scalp & $10(22.2 \%)$ & $4(4 \%)$ & $1(8.3 \%)$ & & \\
\hline Pediculosis capitis & $12(13.3 \%)$ & $16(16.3 \%)$ & $0(0 \%)$ & & \\
\hline Alopecia areata & $7(7.8 \%)$ & $22(22.4 \%)$ & $1(8.3 \%)$ & & \\
\hline Vitilligo in scalp & $1(1.1 \%)$ & $0(0 \%)$ & $00(\%)$ & & \\
\hline Impetigo in scalp & $2(2.2 \%)$ & $2(2 \%)$ & $0(0 \%)$ & & \\
\hline Cicatritial alopecia & $2(2.2 \%)$ & $5(5.1 \%)$ & $0(0 \%)$ & & \\
\hline Toxic alopecia & $1(1.1 \%)$ & $1(1 \%)$ & $0(0 \%)$ & & \\
\hline Post traumatic alopecia & $1(1.1 \%)$ & $2(2 \%)$ & $0(0 \%)$ & & \\
\hline Sebaceous cyst & $1(1.1 \%)$ & $1(1 \%)$ & $0(0 \%)$ & & \\
\hline
\end{tabular}

Table (5): Comparison between different lesions regarding sex

\begin{tabular}{|c|c|c|c|c|}
\hline Hair and scalp disease & $\begin{array}{c}\text { Male } \\
(\mathrm{N}=90)\end{array}$ & $\begin{array}{c}\text { Female } \\
(\mathrm{N}=110)\end{array}$ & $\chi^{2}$ & P-value \\
\hline Hair shaft disease & $0(0 \%)$ & $3(27.3 \%)$ & \multirow{14}{*}{49.1} & \multirow{14}{*}{0.000} \\
\hline Telogen effluvium & $0(0 \%)$ & $16(14.5 \%)$ & & \\
\hline Tractional alopecia & $0(0 \%)$ & $16(14.5 \%)$ & & \\
\hline Tinea capitis & $28(31.1 \%)$ & $7(6.4 \%)$ & & \\
\hline Seborrhic dermatitis & $14(15.6 \%)$ & $24(20.9 \%)$ & & \\
\hline Multiple boils in scalp & $8(8.9 \%)$ & $7(6.4 \%)$ & & \\
\hline Pediculosis capitis & $7(7.8 \%)$ & $21(19.1 \%)$ & & \\
\hline Alopecia areata & $21(23.3 \%)$ & $9(8.1 \%)$ & & \\
\hline Vitilligo in scalp & $0(0 \%)$ & $1(0.9 \%)$ & & \\
\hline Impetigo in scalp & $3(3.3 \%)$ & $1(0.9 \%)$ & & \\
\hline Cicatritial alopecia & $4(4.4 \%)$ & $3(27.3 \%)$ & & \\
\hline Toxic alopecia & $2(2.2 \%)$ & $0(0 \%)$ & & \\
\hline Post traumatic alopecia & $2(2.2 \%)$ & $1(0.9 \%)$ & & \\
\hline Sebaceous cyst & $1(1.1 \%)$ & $1(0.9 \%)$ & & \\
\hline
\end{tabular}

Table 5 this table showed no significant difference value regarding the sex of the patients.

Table (6): Comparison between different lesions regarding residence:

\begin{tabular}{|c|c|c|c|c|}
\hline Hair and scalp disease & Urban $(\mathrm{N}=86)$ & $\begin{array}{c}\text { Rural } \\
(\mathrm{N}=114)\end{array}$ & $\chi^{2}$ & P-value \\
\hline Hair shaft disease & $1(1.2 \%)$ & $2(1.8 \%)$ & \multirow{14}{*}{22.9} & \multirow{14}{*}{0.000} \\
\hline Telogen effluvium & $3(3.4 \%)$ & $13(11.4 \%)$ & & \\
\hline Tractional alopecia & $3(3.4 \%)$ & $13(11.4 \%)$ & & \\
\hline Tinea capitis & $26(27 \%)$ & $9(7.9 \%)$ & & \\
\hline Seborrhic dermatitis & $13(14.8 \%)$ & $25(23.7 \%)$ & & \\
\hline Multiple boils in scalp & $11(13.4 \%)$ & $4(3.5 \%)$ & & \\
\hline Pediculosis capitis & $17(19.8 \%)$ & $11(11.4 \%)$ & & \\
\hline Alopecia areata & $6(7 \%)$ & $24(21.1 \%)$ & & \\
\hline Vitilligo in scalp & $0(0 \%)$ & $1(0.9 \%)$ & & \\
\hline Impetigo in scalp & $2(2.2 \%)$ & $2(1.8 \%)$ & & \\
\hline Cicatritial alopecia & $3(3.6 \%)$ & $4(3.5 \%)$ & & \\
\hline Toxic alopecia & $1(1.2 \%)$ & $1(0.9 \%)$ & & \\
\hline Post traumatic alopecia & $0(0 \%)$ & $3(2.6 \%)$ & & \\
\hline Sebaceous cyst & $1(1.2 \%)$ & $1(0.9 \%)$ & & \\
\hline
\end{tabular}


In Table 6 there is a significant difference value in tinea capitis and pediculosis capitis in urban-rural areas. The is a significant difference value in seborrheic dermatitis and alopecia areata in rural than urban areas.

\section{DISCUSSION}

To the best of our knowledge, no extensive report exists regarding the epidemiology of these disorders in children. Therefore, we sought to evaluate the clinical and epidemiological profile of hair and scalp disorders in children attending the Pediatrics and Dermatology Outpatient Clinic.

In the present study, we found that out of 1000 children attended our clinics, 200 children had scalp disease.

Conti et al. ${ }^{(11)}$ found that out of the 2,640 children who had access to the Dermatology Service in 2009, $190(7.19 \%)$ had a hair or scalp disorder.

In the present study, we noticed that; male to female ratio was $0.8: 1$. Afsar et al. ${ }^{(12)}$ noticed; an equal sex distribution was seen in a total of patients with a male: female ratio of $1: 1$, which was reported to be between $0.9: 1$ and 1:1.6 in other studies ${ }^{(13,14)}$.

There was only a slight male preponderance in allergic skin diseases and infectious disease groups, whereas papulo-squamous disorders, vascular and lymphatic anomalies, and disorders of skin appendages were slightly more prevalent in females. This may be attributed to aesthetic reasons. Also, the female preponderance in primary school children and preadolescents may be attributed to aesthetic concerns compatible with age ${ }^{(\mathbf{1 2})}$.

The age groups with the largest numbers of children were those of children aged less than 5 years. This is similar to results from several studies that reported that infants as the largest population of children by age group ${ }^{(15)}$. Although other studies have reported that the largest and smallest numbers of children were those of children aged 10-12 and 0-3 years ${ }^{(\mathbf{1 3})}$.

The pattern of skin diseases in the pediatric age group varies from one country to another and within the same country from one state to another due to various climatic, cultural, and socioeconomic factors (16). In the present study, the largest percent of hair diseases in age below five years is infectious which reflects the bad environmental status of this group. This was confirmed as we denoted that $52 \%$ of the included patients were from rural areas.

The infants are mostly confined to their household, while preschool children aged one to five years are exposed to their neighborhood. Thus, childhood age may be considered as a surrogate marker for environmental risks ${ }^{(17)}$.

In the current study, malnutrition was evident in $58 \%$ of children with scalp diseases. Nutritional deficiency disorders reported in our study are more than studies by Negi et $\boldsymbol{a l}$. (18) (17.5\%), Singh and Nupur (19) (5.38\%), and Jawade et al. ${ }^{(20)}(3.82 \%)$. This may reflect better nutritional status and nutrition ignorance in our region.

In accordance with our findings, the association of nutrition with skin and hair changes emanates primarily on protein-energy malnutrition (21). It was found that; chronic type of hair loss may be due to zinc deficiency despite the absence of characteristic signs of zinc deficiency, and this may highlight the idea of how much was common the phenomena of zinc deficiency ${ }^{(4)}$.

In the present study alopecia areata represented $15 \%$ of the studied patients. In a previous study, the $1.32 \%$ prevalence of alopecia is within the range of $1-2 \%$ reported previously ${ }^{(22)}$. An association was observed between alopecia areata and autoimmune or immune-mediated diseases as previously reported. As, about $20 \%$ of patients with alopecia areata were reported to have nail changes, with pitting being the most common feature ${ }^{(23)}$.

In the present study, we denoted male predominance of alopecia areata. This can be explained as AA has bimodal age distribution (pediatrics and adult) ${ }^{(6)}$. Alopecia areata (AA) was more frequently seen in female patients as in a previous study ${ }^{(4)}$.

In the present study, most patients with alopecia areata (25\%) belonged to the age group 510 years. Previously, it was reported that AA has bimodal age distribution (pediatrics and adult) it is less likely to occur in children below 2 years of age (6).

We identified that $19 \%$ of the included patients had seborrheic dermatitis. The prevalence of seborrheic dermatitis was examined in a population of 1,634 preschool-aged children from Victoria, Australia, and it was found in about $10 \%$ (24).

In the present study, Tinea capitis was evident in $17.5 \%$ of the study population. Moneib et al. (25) found that; Tinea capitis showed the highest percentage $(30.2 \%)$ among the cases, another study conducted in Jordan reported that tinea capitis was evident in $40 \%$ of cases ${ }^{(4)}$.

In the present study, we found the highest prevalence of tenia capitis was in the age group 510 years. Nageswaramma et al. ${ }^{(3)}$ found that the highest incidence of tenia capitis was seen in 3-7 years' age group and they found a slight female preponderance was seen, with females forming $52 \%$ of the noninflammatory cases $(55.5 \%)$, which was more common than inflammatory cases (33.7). 
In the current study, tinea capitis affected patients in urban areas more than those in rural areas. In accordance with our findings, Ghannoum et al. (26), found that tinea capitis was more prevalent in urban areas (75.2\%) compared with rural areas $(24.8 \%)$. Our result can be explained by the increased number of patients seeking medical attention for their scalp lesions, in turn increasing the diagnosed level of tinea capitis in a given area ${ }^{(27)}$. However, another study revealed higher evidence of tinea capitis in rural areas ${ }^{(28)}$.

In the present study, $14.5 \%$ of females suffer from tractional alopecia, while no male had tractional alopecia. Nnoruka et al. ${ }^{(29)}$ found that females within the same age range were more predisposed to traction alopecia as they grew older, with their hair becoming more tangled and difficult to comb. Haircare practice is geared towards making the hair more manageable and tidier. Therefore, girls have their hair relaxed or blowdried before braiding or plaiting. Traction alopecia thus occurs quite early. Most parents were unperturbed, however, and all cases of traction alopecia recorded in this study were incidental findings and not the main reason for consultation for the child ${ }^{(29)}$.

Etiological agents identified were Staphylococcus aureus (44.5\%), S. aureus and Streptococcus pyogenes combined (28\%), and S. pyogenes alone (13.3\%). Other organisms included were coagulase-negative Staphylococci (30). Antibiotic sensitivity was done. S. aureus showed $75.5 \%$ resistance to penicillin and $45.4 \%$ resistance to tetracycline. $S$. pyogenes was resistant to streptomycin in $14.4 \%$ of the cases and tetracycline in $14.8 \%$ of the cases ${ }^{(31)}$.

In the present study, pediculosis was evident in $14 \%$ of the included patients. Kassiri and Esteghali ${ }^{(32)}$ denoted that the prevalence of head lice in primary school students was found to be $5.7 \%$.

In this research, the ratios of children with head lice infestations were dissimilar based on the age group, which may have been related to the behavioral differences in the various age groups as it was increased in age group less than 10 years reaching $0 \%$ in age group more than ten years. Diff erences in the infestation rates between the age categories (6 - 13 years old) have been shown by many investigations. It seems as though the younger age groups are dependent on their parents for the cleaning, combing, and washing of their hair. This can contribute to the early discovery of head lice before complete infestation ${ }^{(33)}$.

Also, we found that $11.4 \%$ of patients belong to rural areas had pediculosis. The infestation rates among the primary schools in both the urban and rural areas were not significant. Therefore, the differences in the head lice infestation rates may be based on the family income, economic status, overcrowded houses, degree of the head to head contact, control methods, personal hygiene, primary school head lice strategy, parents' literacy, or situations in the health care system ${ }^{(32)}$.

In the present study, telogen effluvium was found in $8 \%$ of cases. This percentage is less than the previously reported percentage by Al-Refu ${ }^{(4)}$ as he found that the presentation with hair loss due to telogen effluvium was seen in nearly $17 \%$ of cases and was commonly due to preceding history of fever. The difference can be explained as his study aimed only to assess hair loss among pediatrics, not all hair lesions.

In the present study, $41.7 \%$ of children aged above 10 years were presented with Telogen effluvium and all of the cases with Telogen effluvium were females. Nageswaramma et $\boldsymbol{a l} .{ }^{(3)}$ found that Telogen effluvium was more common in females. The mean age of presentation was around 8 years.

Previously it was found that telogen effluvium resulting from a traumatic stimulus, which shows diffuse hair loss that does not produce clear areas and it may be higher than what is seen in the adult population, as the common causes of telogen effluvium and iron deficiency anemia are common in children ${ }^{(34)}$. This is in accordance with our findings as we denoted that $11.4 \%$ of rural cases had telogen effluvium.

Cicatricial alopecia was found in $3.5 \%$ of our studied population. Khumalo et al. ${ }^{(35)}$ found a low prevalence of Cicatricial alopecia (1.9\%) in adults, most of whom were older than 50years, and no Cicatricial alopecia in children, a surprising finding given that the common hair grooming practices, such as chemical relaxer use and braids linked to Cicatricial alopecia in African American women, are also used in this African population. The difference in results may be explained by the difference in ethnicity of the studied populations.

In the present study bacterial skin infection like; impetigo and multiple boils were evident in $2 \%$ and $7.5 \%$, respectively. Nageswaramma $\boldsymbol{e t}$ al. (3) found that infectious causes were the most common causes of hair disorders. Various factors such as poverty, malnutrition, overcrowding, and poor hygiene were responsible for the higher incidence in the lower socioeconomic group. Seasonal variation was observed. More cases were reported in the hot and rainy climate. Males and females were equally affected. Older children were more affected than younger children ${ }^{(36)}$. 
Essmat et al. ${ }^{(28)}$ found that impetigo was found in $13.37 \%$ of cases. Impetigo was common in rural areas with lower hygiene than urban areas and was also common in children with a low social score. Further, impetigo affected females more than males, which may be attributed to the highly significant concomitant infestation with pediculosis capitis. Impetigo was common in rural areas with lower hygiene than urban areas and was also common in children with a low social score, tinea capitis affected, those in rural areas more than those in urban areas. However, in the present study, there was no significant difference between the distribution of cases with impetigo regarding sex or residence.

\section{CONCLUSION}

Hair and scalp disorder in children is a common complaint in pediatrics clinics, and it is considered a challenge for pediatricians for reaching a proper diagnosis and therapy. Also, this is an annoying problem for parents who worry about their children. Early management is needed, as it affects the normal physical and mental growth of children.

\section{RECOMMENDATIONS}

- Early management is needed, as it affects the normal physical and mental growth of children.

- Community-based studies need to be carried out to confirm and explore our findings to determine the magnitude and pattern of different types of dermatoses affecting that age group, which could be a basis for future health plans.

- The routine use of dermoscopy in the clinical evaluation of scalp and hair disorders will improve the diagnostic capability beyond simple clinical inspection by revealing novel features of disease leading to better management.

- Health promotion and health education interventions are recommended to promote good hygiene, better living conditions, early identification, and treatment.

\section{REFERENCES}

1. Bedocs L, Bruckner A (2008): Adolescent hair loss. Curr Opin Pediatr., 20:431-435.

2. Sarifakioglu E, Yilmaz A, Gorpelioglu $\mathrm{C}$ et al. (2012): Prevalence of scalp disorders and hair loss in children. Cutis., 90:225-229.

3. Nageswaramma $\mathrm{S}$, Lakshmi Sarojini $\mathrm{V}$ et al. (2017): A clinico-epidemiological study of pediatric hair disorders. Indian $\mathbf{J}$ Paediatr Dermatol., 18(2):100-3.
4. Al-Refu K (2013): Hair Loss in Children: Common and Uncommon Causes; Clinical and Epidemiological Study in Jordan. Int J Trichology, 5(4): 185-189.

5. Hamm H (2013): Acquired alopecia in childhood. Hautarzt. 2013; 64:371-9; quiz 380-1.

6. Castelo-Soccio $\mathbf{L}$ (2014): Diagnosis and management of alopecia in children. Pediatr Clin North Am., 61(2):427-42.

7. WHO (2008): WHO Global Database on Child Growth and Malnutrition.http://www.who.int/nutgrowthdb/data base/countries/egy/en

8. Garrow J, Webster J (1985): Quetelet's index $(\mathrm{W} / \mathrm{H} 2)$ as a measure of fatness. Int J Obes., 9(2):147-53.

9. Kasr El Eini (2004): Standard percentile Egyptian curves Cairo University and National Research Centre, Cairo. https://www.researchgate.net/publication

10. Cole $T$, Bellizzi $M$, Flegal $K$ et al. (2000): Establishing a standard definition for child overweight and obesity worldwide: international survey. BMJ., 320:1240-3.

11. Conti G, Heckman J, Pinto R (2016). 'The health effects of two influential early childhood interventions on health and healthy behaviors. Economic Journal, 126(596): 28-65.

12. Afsar F, Diniz G, Aktas S (2017): Pediatric Dermatopathology: An overview. Archivos Argentinos de Pediatria. Arch Argent Pediatr., 115(4):377-381.

13. Wenk C, Itin P (2003): Epidemiology of pediatric dermatology and allergology in the region of Aargau, Swizerland. Pediatr Dermatol., 20:482-7.

14. Karthikeyan $\mathrm{K}$, Thappa D, Jeevankumar B (2004): Pattern of Pediatric dermatoses in a referral center in South India. Indian Pediatr., 41:373-7.

15. Kabir S, Supriya M, Rashmi S et al. (2009): The Spectrum of Skin Disease Among Indian Children. Pediatric Dermatology, 26: 6-13.

16. Sayal S, Bal A, Gupta C (1998): Pattern of skin diseases in the pediatric age group and adolescents. Indian J Dermatol Venereol Leprol., 64:117-9.

17. Mitra M, Mitra C, Gangopadhyay D (2005): Effect of environment on pediatric dermatoses. Indian J Dermatol., 50:64-7.

18. Negi K, Kandpal S, Parsad D (2001): Pattern of skin diseases in children in the Garhwal region of Uttar Pradesh.Indian Pediatr., 38(1):77-80.

19. Singh R, Nupur $P$ (2018): Pattern of pediatric dermatoses in a tertiary care center of Patna, Bihar. Int J Sci Res., 7(6):22-6.

20. Jawade S, Chugh V, Gohil S et al. (2015): A clinico-etiological study of dermatoses in the pediatric age group in the tertiary health care center in the South Gujarat region. Indian J Dermatol., 60:635-38.

21. Gilbert $S$ (1993): Eating disorders. In: Garrow JS, James WPT, eds. Human Nutrition, Dietetics, 9th ed. Edinburgh: Churchill Livingstone, Pp. 752-60. 
22. Hordinsky M (2013): Overview of Alopecia Areata. Journal of Investigative Dermatology Symposium Proceedings, 16(1): 13-15.

23. Gedik A, Cakir E, Ozkaya E et al. (2014): Can appropriate diagnosis and treatment of childhood asthma reduce excessive antibiotic usage? Med Princ Pract., 23:443-447.

24. Foley P, Zuo Y, Plunkett A et al. (2003): The frequency of common skin conditions in preschoolaged children in Australia: seborrheic dermatitis and pityriasis capitis (cradle cap) Arch Dermatol., 139:318-322.

25. Moneib H, El-Shiemy S, Saudi W et al. (2017): Hair loss among a group of Egyptian children. Journal of the Egyptian Women's Dermatologic Society, 14(1): 9-24.

26. Ghannoum M, Wraith L, Cai B et al. (2008): Susceptibility of dermatophyte isolates obtained from a large worldwide terbinafine tinea capitis clinical trial. Br J Dermatol., 159: 711-713.

27. Woldeamanuel Y, Leekassa R, Chryssanthou E et al. (2005): Prevalence of tinea capitis in Ethiopian schoolchildren. Mycoses,20: 137-141.

28. Essmat S, El Safoury O, El-Hanafy G (2014): Pattern of skin diseases among preschool and primary school-aged children in Dermatology Damietta Hospital. Journal of the Egyptian Women's Dermatologic Society, 11(3):181-186.
29. Nnoruka E, Obiagboso I, Maduechesi C (2007): Hair loss in children in South-East Nigeria: common and uncommon cases. Int J Dermatol., 46(1):18-22.

30. Malhotra S, Malhotra S, Dhaliwal G et al. (2012): Bacteriological study of pyodermas in a tertiary care dermatological center. Indian $\mathbf{J}$ Dermatol., 57:358-61.

31. Mathews M, Garg B, Kanungo $R$ (1992): A clinico-bacteriological study of primary pyodermas in children in Pondicherry. Indian $\mathrm{J}$ Dermatol Venereol Leprol., 58:183-7.

32. Kassiri H, Esteghali E (2016): Prevalence Rate and Risk Factors of Pediculus capitis Among Primary School Children in Iran, Arch Pediatr Infect Dis., 4(1):26390-3.

33. Alempour-Salemi J, Shayeghi $M$, Zeraati $\mathrm{H}$ et al. (2003): Some Aspects of Head Lice Infestation in Iranshahr Area (Southeast of Iran) Iranian J of Pub Health, 32(3):60-63.

34. Grover C, Khurana A (2013): Telogen efflivium. Indian J Dermatol Venereol Leprol., 79:591-603.

35. Khumalo N, Jessop S, Gumedze F et al. (2007): Hairdressing and the prevalence of scalp disease in African adults. British Journal of Dermatology, 157(5): 981-988.

36. Mandt N, Vogt A, Blume-Peytavi U (2004): Differential diagnosis of hair loss in children. J Dtsch Dermatol Ges., 2:399-411. 